\title{
Takayasu arteritis presenting with massive cerebral ischemic infarction in a 15-year-old girl: a case report
}

\author{
Mohinish S.*, Dhanalakshmi K., Sushma Veeranna Sajjan, Priyanka K.
}

Department of Paediatrics, Bangalore Medical College and Research Institute, Bangalore, Karnataka, India

Received: 25 November 2019

Accepted: 30 December 2019

\section{*Correspondence:}

Dr. Mohinish S.,

E-mail: monishpaeds@gmail.com

Copyright: (C) the author(s), publisher and licensee Medip Academy. This is an open-access article distributed under the terms of the Creative Commons Attribution Non-Commercial License, which permits unrestricted non-commercial use, distribution, and reproduction in any medium, provided the original work is properly cited.

\begin{abstract}
Takayasu arteritis is a relatively rare type of large-vessel arteritis that primarily affects the aorta and its major branches, the coronary arteries, and the pulmonary arteries. Depending on the different groups of blood vessels involved in the disease process, the clinical presentation of Takayasu arteritis varies. Here we report a case of a girl presenting with a debilitating massive cerebral ischemic infarct that turned out to be a relatively rare first presentation of Takayasu arteritis. Case report of 15 years old adolescent female hailing from lower socio-economic status with past history of chronic headache, no significant family history, completely immunized presented with sudden onset weakness of right upper and lower limbs, which progressed over 1day with aphasia (recovering) with deviation of angle of mouth to left side On examination left radial ,carotid artery not palpable. Her laboratory results showed an elevated C-reactive protein and erythrocyte sedimentation rate, and subsequent CT angiography demonstrated narrowing and occlusion of the major branches of her aortic arch. We report the case of a patient with Takayasu arteritis presenting with a massive cerebral ischemic infarct and review the current literature on this topic. Conclusion of takayasu arteritis is a relatively rare disease with various and sometimes devastating clinical manifestations, such as massive cerebral ischemic infarction as in our case. Currently, there are multiple diagnostic tools and treatment options available, and more under investigation. Early, appropriate diagnosis and initiation of proper therapy could avoid further progression and reduce complications of the disease.
\end{abstract}

Keywords: Coronary artery, Inflammatory arteritis, Pulseless disease, Stroke in young, Subclavian artery, Takayasu's arteritis

\section{INTRODUCTION}

Takayasu's Arteritis (TA), also known as aorto-arteritis and pulseless disease, is a rare condition. It is a form of granulomatous arteritis, which affects large- and medium sized arteries, primarily the aorta and its large branches as well as proximal portions of pulmonary, coronary, and renal Arteries. ${ }^{1}$

Initially, there are mononuclear cell infiltrations in the adventitia and granulomas with Langerhans cells in the media, followed by disruption of the elastin layer and subsequent massive medial and intimal fibrosis. These lesions result in segmental stenosis, occlusion, dilatation, and aneurysmal formation in the affected vessels. Diminished or absent pulses are present in $84-96 \%$ of patients, associated with limb claudication and blood pressure discrepancies between the two arms. ${ }^{2}$ The symptoms are secondary to the involved artery, and it may evolve into a life-threatening condition.

\section{CASE REPORT}

A 15-year-old girl presented with complaints of headache for past 2 months duration. She was noticed to have weakness involving Right upper limb and lower limb as when she was having food. Initially weakness noted over right upper limb in form of difficulty in mixing food 
while eating, difficulty in taking the food to mouth. By couple of hours, weakness progressed proximally in the form of difficulty in lifting the hands above the head. Over next 4-6 hours, weakness progressed to involve Right lower limb in form of difficulty in gripping slippers, difficulty in getting up from siting position, walking with limping. Meanwhile she developed total loss of movements in both Right upper limb and lower limb. Difficulty in lifting head from pillow noted. Weakness associated with deviation of angle of mouth towards Left side.

Complaints of reduced verbalization noticed alongside loss of movements and weakness on the Right side, which gradually recovered to some extent (in 1 day) to reduce speech output with preserved comprehension and frailness of Right upper and lower limb. No history of any medications such as oral contraceptive pills. There was no family history of any early onset cerebral vascular accident events. She denied the use of alcohol, tobacco products or recreational drugs.

On physical examination, she was conscious, lying on bed with upper limbs in extended position, extension at right elbow, hip, knee, and extended foot (Figure 1).

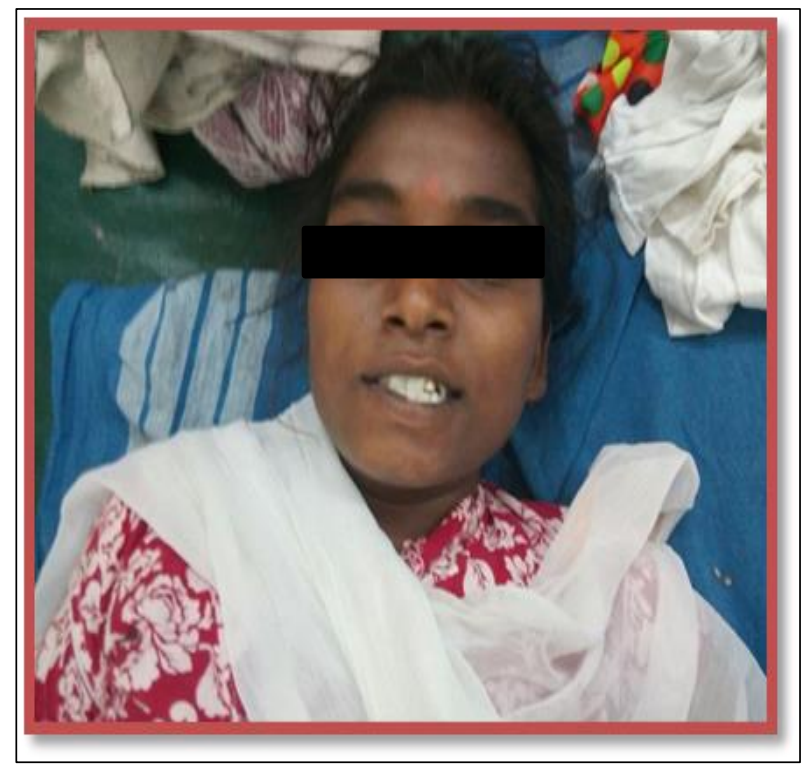

Figure 1: External appearance showing deviation of angle of mouth.

Her heart rate was 92 beats per minute, felt well in right radial artery, left radial and carotid artery not felt. All the peripheral pulses were well felt except left radial and left carotid. Right carotid bruit heard. Peripheral pulses felt in lower limbs. Blood Pressure (BP) was recorded as 100/60 $\mathrm{mmHg}$ in right upper limb, left upper limb BP not recordable and lower limb BP $128 / 72 \mathrm{mmHg}$. She was able to open her eyes and left sided facial droop noted (Figure 2). There was obvious right-sided hemiparesis with a positive Babinski sign. The rest of her neurological, systemic, and general physical examinations were unremarkable.

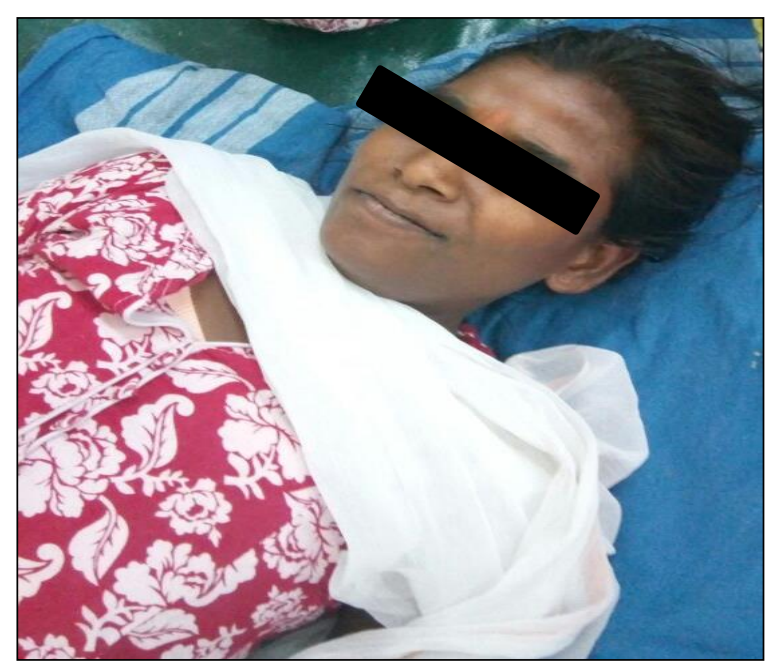

Figure 2: LEFT sided facial palsy.

Her laboratory test results showed white blood cells (WBCs) of 11.9x109/L, Hemoglobin (Hb) of $9.54 \mathrm{~g} / \mathrm{dl}$, and platelets (PLTs) of 205x109/L. Thyroid profile normal. ESR $98 \mathrm{~mm} / \mathrm{hr}$. CRP=elevated. Homocysteine level elevated mildly. ECG (Figure 3) shows normal findings for age.

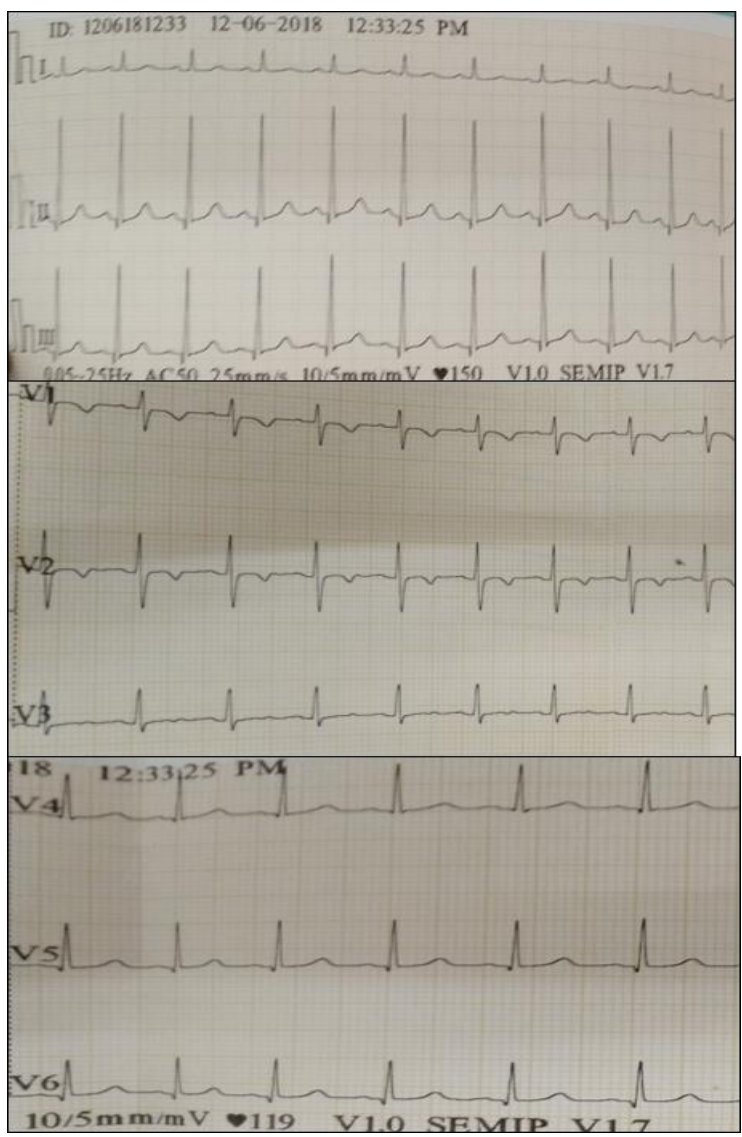

Figure 3: Normal ECG. 
MRI brain shows frank restricted diffusion at left caudate nucleus; putamen suggestive of acute ischemia (Figure 4,5).

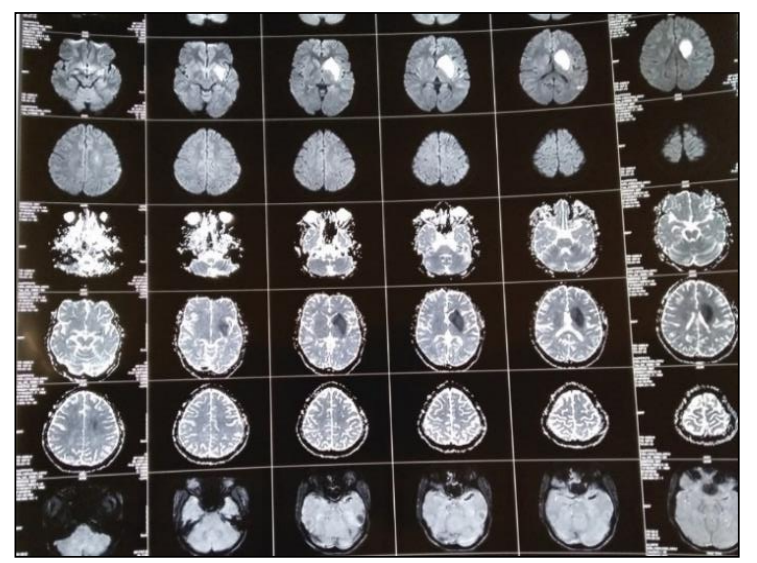

Figure 4: MRI brain shows restricted diffusion at LEFT caudate nucleus.

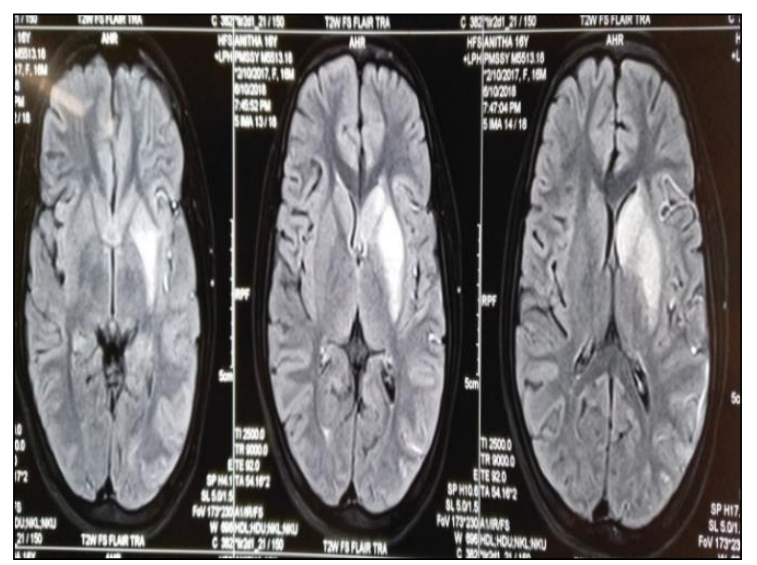

Figure 5: MRI brain shows acute ischemic changes.

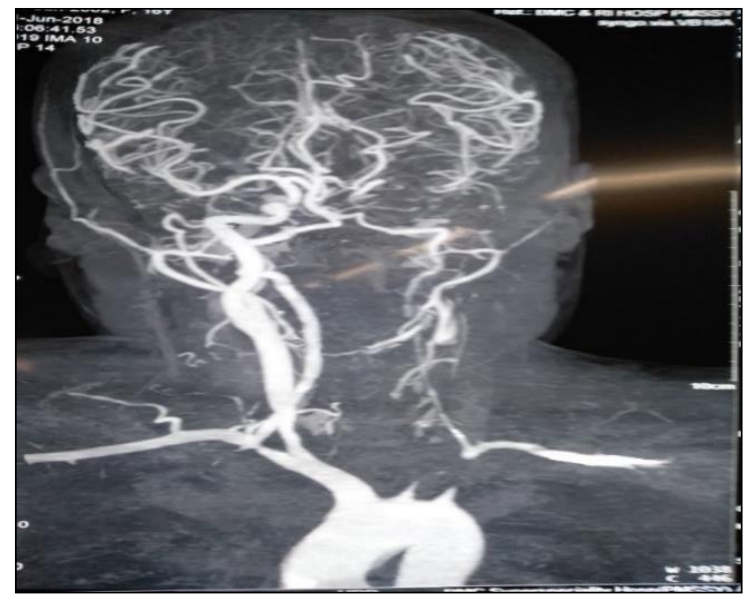

Figure 6: CT angio of neck shows soft tissue cuffing around major vessels.

CT angiogram of hean and neck shows Evidence of circumferential soft tissue cuffing noted involving Aorta, Brachiocephalic trunk, Left CCA, L SCA, L vertebral arteries causing severe luminal narrowing of Right CCA, SCA, Vertebral arteries with minimal faint flow noted. (Figure 6,7,8) Reformation noted at M1 segment of Left sided MCA evidence of complete cut off noted involving proximal M1 segment of LMCA with associated Collateralization, reformation noted at M2 segment.

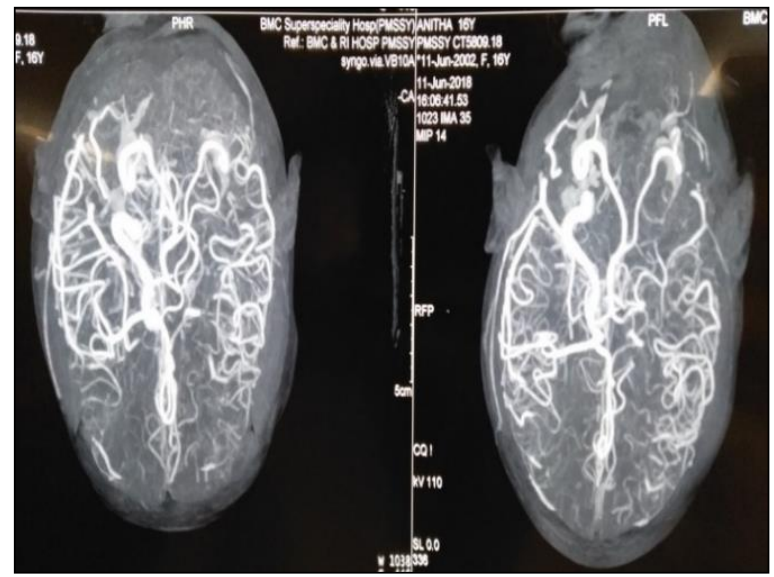

Figure 7: CT angio of head and neck shows reformation at M1 segment.

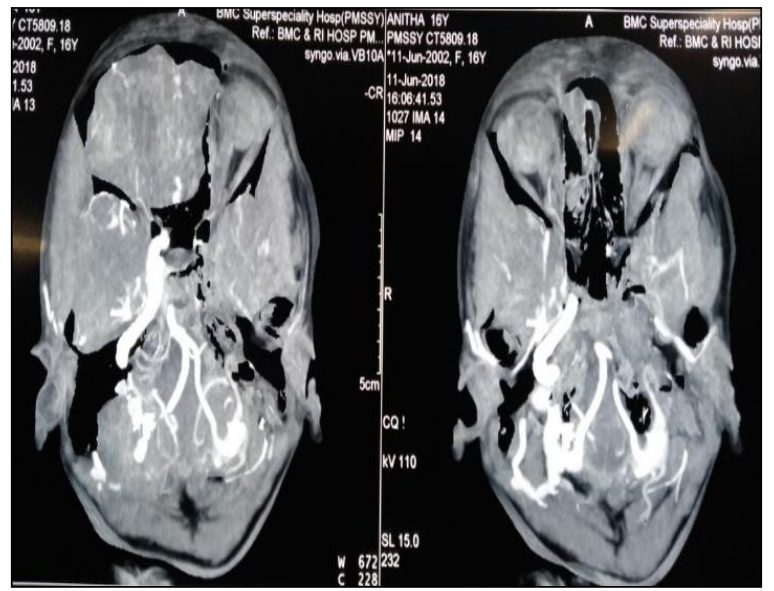

Figure 8: CT ANGIO of head and neck shows reformation at $\mathrm{M} 1$ segment.

The diagnosis of Takayasu arteritis type 2a was made according to the revised Ishikawa diagnostic criteria and the angiographic classification of Takayasu arteritis put forward at the Takayasu Conference $1994 .{ }^{1}$ Patient was started on steroids and improvement noted.

\section{DISCUSSION}

Author present a case of a large ischemic stroke in a 15year old girl, with no known risk factors. There were no signs of atherosclerosis and no evidence of developmental abnormalities affecting the aorta such as coarctation or Marfan syndrome. There was affection of the large arteries, thus raising suspicion of large artery vasculitis. The ESR and CRP were elevated, indicating inflammation. The possibility of giant cell arteritis was 
considered but found unlikely due to the patient's young age with only slight ESR elevation. There were no findings indicating rheumatoid arthritis, SLE, or Wegener granulomatosis. With the characteristic findings on Doppler ultrasonography and CT angiography with stenosis, occlusion, and thickened arterial walls, in addition to blood tests indicating acute phase reaction with elevated CRP, the diagnosis of childhood TA was affirmed. It was classified as type IIa in accordance with the Hata angiography-based classification. ${ }^{3}$

Systemic symptoms as fever, weight loss, headache, and raised inflammatory markers are common at TA onset. ${ }^{4}$ However, the nonspecific nature of the presenting complaints together with the lack of specific disease markers often causes a delay in diagnosis. ${ }^{5}$ Therefore, many patients already suffer from symptoms of arterial claudication and end organ ischemia at the time of diagnosis. These complications, which often are irreversible, include cardiovascular, pulmonary, and neurological complications. The most common cardiovascular complication is hypertension, mainly caused by renal artery stenosis or aortic narrowing and aortic fibrosis. ${ }^{6}$ Other cardiovascular complications are myocarditis, coronary artery involvement, aortic regurgitation, aortic aneurysms, and dissection of the aorta. $^{7}$

Neurological symptoms include orthostatic hypotension and syncope, headache, and amaurosis fugax. ${ }^{8}$ Stroke is a potential serious complication of TA and has been reported as the first manifestation of the disease. ${ }^{9}$ In a study of 45 patients with TA followed up in a Turkish hospital, cerebrovascular events were the initial complaint in $13 \%$, and of 142 patients in a study from South Africa $20 \%$ were identified with a primarily cerebrovascular presentation. ${ }^{10,11}$

Several criteria for the diagnosis of Takayasu's arteritis were proposed by the American College of Rheumatology in 1990. They included (1) Age at onset of less than 40 years, (2) Claudication of the extremities, (3) Decreased brachial artery pressure, (4) Blood pressure difference of more than $10 \mathrm{mmHg}$, (5) Bruit at the subclavian arteries and aorta, and (6) Aortograph abnormalities. ${ }^{12}$ The presence of three of the six criteria was required, which was associated with a sensitivity of $90.5 \%$ and a specificity of $97.8 \%$. Pathology on angiography is a mandatory diagnostic criterion for childhood-onset TA. ${ }^{13}$

Digital suppression angiography is the gold standard, but MR angiography and CT angiography are non-invasive alternatives. Ultrasonography may show a hypo echoic thickening of the vessel walls. ${ }^{14}$ Fluorodeoxyglucose Positron Emission Tomography (PDGPET) may yield diagnostic information about the degree and site of inflammation. $^{15}$ In this patient, initial physical examination demonstrated reduced radial pulses on both sides, which raised suspicion of Takayasu arteritis. According to a recent study, individual physical examination findings had poor sensitivity and good to excellent specificity. ${ }^{16}$ As a result, the historical Ishikawa clinical classification of Takayasu arteritis is still widely used to determine prognosis and treatment plan.

The presentation of this patient is relatively rare and devastating, thus raising the question of the etiology of her ischemic stroke. Several imaging tools were utilized in our case. The method we did not use on this patient is Positron Emission Tomography/Computed Tomography (PET/CT) due to issues of cost and radiation exposure. As a functional imaging modality, PET/CT is able to pick up sites of active inflammation, which makes it a useful tool in detecting the early-stage vascular lesions and monitoring the activity of the disease.

In regard to treatment options of Takayasu arteritis, corticosteroid remains the first-line medical therapy in the active disease process. ${ }^{17}$ In this patient, since the clinical and laboratory manifestations were both improving with steroid use only, other immunosuppressants were not used. ${ }^{18}$ Surgical interventions such as angioplasty and vascular reconstruction are also recommended for severe stenosis or occlusion of critical arteries, between which surgical bypass is considered to have superior potency but more serious early postoperative complications as well. ${ }^{19}$

As seen in this patient, Takayasu arteritis can cause devastating damage to the overall health condition and quality of life, or even be life-threatening sometimes. ${ }^{20}$ If diagnosed at an early stage, the disease could be controlled with the standard therapies discussed earlier, as well as surgical intervention if critical vessels are involved, so that debilitating and irreversible complications such as massive cerebral ischemic infarction may not ensue. ${ }^{21}$

\section{CONCLUSION}

Takayasu arteritis is a relatively rare disease with various and sometimes devastating clinical manifestations, such as the massive cerebral ischemic infarct in this case. Early, appropriate diagnosis and initiation of proper therapy could avoid further progression and reduce complications of the disease. TA, especially with stroke as the first presentation of the disease, is uncommon. It should however be kept in mind as a cause of cerebrovascular disease, especially in the young.

\section{Funding: No funding sources \\ Conflict of interest: None declared \\ Ethical approval: Not required}

\section{REFERENCES}

1. Toshihiko N. Current status of large and small vessel vasculitis in Japan. Intern $\mathbf{J}$ Cardiol. $1996 ; 54: 91-8$. 
2. Ishikawa K. Diagnostic approach and proposed criteria for the clinical diagnosis of Takayasu's arteriopathy. J Am Coll Cardiol. 1988;12:964-72.

3. Kothari SS. Takayasu's's arteritis in children-a review. Images Paediatr Cardiol. 2001;3:4-23.

4. Subramanyan R, Joy J, Balakrishna KJ. Natural history of aorto-arteritis. Circulat. 1989;80:429-37.

5. Arend WP, Michel BA, Bloch DA, Hunder GG, Calabrese LH, Edworthy SM, et al. The American College of Rheumatology 1990 criteria for the classification of Takayasu arteritis. Arthritis Rheumat. 1990;33(8):1129-34.

6. Johnston SL, Lock RJ, Gompels MM. Takayasu arteritis: a review. J Clin Pathol. 2002;55(7):481-6.

7. Hata A, Noda M, Moriwaki R, Numano F. Angiographic findings of Takayasu arteritis: new classification. Intern J Cardiol. 1996;54:155-63.

8. Bicakcigil M, Aksu K, Kamali S, Ozbalkan Z, Ates A, Karadag O, et al. Takayasu's arteritis in Turkeyclinical and angiographic features of 248 patients. Clin Exp Rheumatol. 2009;27(1):59-64.

9. Silver M. Takayasu's arteritis-an unusual cause of stroke in a young patient. Western $\mathbf{J}$ Emerg Med. 2012;13(6):484.

10. Mathew AJ, Goel R, Kumar S, Danda D. Childhood onset Takayasu arteritis: an update. Int $\mathbf{J}$ Rheum Dis. 2016;19(2):116-26.

11. Gao S, Wang R. Takayasu arteritis presenting with massive cerebral ischemic infarction in a 35-yearold woman: a case report. J Med Case Report. 2013;7(1):179.

12. Arthritis Rheum 33:1129, 1990. From Hellmann DB: Takayasu's arteritis. In Imboden JB, Hellmann DB, Stone JH eds: Current Rheumatology Diagnosis and Treatment. New York, Lange Medical Books/McGraw-Hill, 2004:245.
13. Stone JH, Imboden JB, Hellmann DB. Current rheumatology diagnosis and treatment. New York: Lange Medical Books/McGraw-Hill; 2004:2007.

14. Hoffmann M, Corr P, Robbs J. Cerebrovascular findings in Takayasu disease. $\mathrm{J}$ Neuroimag. 2000;10(2):84-90.

15. Choe YH, Kim DK, Koh EM, Do YS, Lee WR. Takayasu arteritis: diagnosis with MR imaging and MR angiography in acute and chronic active stages. Journal of Magnetic Resonance Imaging: An Offici J Intern Soci Mag Resona Med. 1999;10(5):751-7.

16. Sikaroodi H, Motamedi M, Kahnooji H, Gholamrezanezhad A, Yousefi N. Stroke as the first manifestation of Takayasu arteritis. Acta Neurologica Belgica. 2007;107(1):18.

17. Hall ST, Barr W, Lie JT, Stanson AW, Kazmier FJ, Hunder GG. Takayasu arteritis. A study of 32 North American patients. Med. 1985 Mar;64(2):89-99.

18. Mathew AJ, Goel R, Kumar S, Danda D. Childhood-onset Takayasu arteritis: an update. Intern J Rheumat Dis. 2016;19(2):116-26.

19. Koide K. Takayasu arteritis in Japan. Heart Vessel Suppl 1992;7:48-54.

20. Tyagi S, Sharma VP, Arora R. Stenting of the aorta for recurrent, long stenosis due to Takayasu's arteritis in a child. Pediatr Cardiol.1999;20(3):215-7.

21. Serra R, Butrico L, Fugetto F, Chibireva MD, Malva A, De Caridi G, et al. Updates in pathophysiology, diagnosis and management of Takayasu arteritis. Annal Vascular Surg. 2016;35:210-25.

Cite this article as: Mohinish S, Dhanalakshmi K, Sajjan SV, Priyanka K. Takayasu arteritis presenting with massive cerebral ischemic infarction in a 15year-old girl: a case report. Int J Contemp Pediatr 2020;7:449-53. 